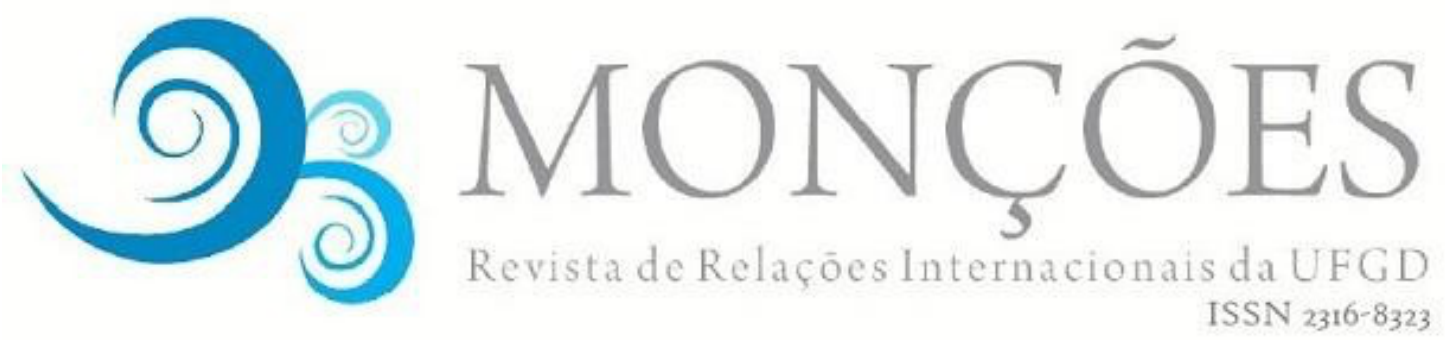

\title{
DEPENDÊNCIA E AUTONOMIA NAS POLÍTICAS EXTERNA E TECNOLÓGICA DO BRASIL, 1951-791
}

\author{
DEMÉTRIO GASPARI CIRNE DE TOLEDO \\ Universidade Federal do ABC, UFABC \\ Bacharelado em Relações Internacionais / Programa de Pós-Graduação em Economia \\ Política Mundial \\ São Bernardo do Campo/Santo André, São Paulo, Brasil \\ ORCID: 0000-0003-0501-2337 \\ demetrio.toledo@ufabc.edu.br
}

\begin{abstract}
Resumo: Este artigo examina um conjunto de políticas externas do Brasil do ponto de vista de suas conexões com as políticas tecnológicas no segundo governo Vargas (1951-4) e nos governos Kubitschek (1956-61), Jânio Quadros e João Goulart (1961-4), Costa e Silva (19679), Médici (1969-74) e Geisel (1974-9). A partir de uma discussão sobre os vínculos entre dependência e autonomia tecnológica nas relações centro-periferia do capitalismo mundial, investiga as convergências entre política externa e política tecnológica. A hipótese que move o trabalho é que ao longo do período 1951-79 os formuladores das políticas externa e tecnológica se tornaram crescentemente conscientes da relação entre autonomia tecnológica e desenvolvimento, e buscaram criar sinergias entre uma política e outra. A análise desses dois conjuntos de políticas permite compreender as prioridades e o real alcance e constrangimentos que uma impôs à outra.
\end{abstract}

Palavras-chave: dependência tecnológica; autonomia; política externa.

\section{DEPENDENCE AND AUTONOMY IN BRAZIL'S FOREIGN AND TECHNOLOGICAL POLICIES, 1951-79}

\begin{abstract}
This article examines a set of Brazilian foreign policies from the point of view of its connections with technological policies in the second Vargas government (1951-54) and the Kubitschek (1956-61) governments, Jânio Quadros e João Goulart (1961-4), Costa e Silva (1967-9), Medici (1969-74) and Geisel (1974-9). Starting with a discussion of the relationship between dependence and technological autonomy in the center-periphery relations of world capitalism, it investigates the convergences between foreign policy and technological policy. According to the hypothesis that moves this work, during that period the formulators of foreign and technological policies became increasingly aware of the relationship between technological autonomy and development, and sought to create synergies between both policies. The analysis of these two sets of policies makes it possible to understand the priorities and the real scope and constraints that one imposed on the other.
\end{abstract}

Keywords: technological dependence; autonomy; foreign policy.

\section{DEPENDENCIA Y AUTONOMÍA EN LAS POLÍTICAS EXTERNA Y TECNOLÓGICA DE BRASIL, 1951-79}

\footnotetext{
${ }^{1}$ O presente trabalho foi realizado com apoio da Coordenação de Aperfeiçoamento de Pessoal de Nível Superior - Brasil (CAPES) - Código de Financiamento 001.
} 
Resumen: Este artículo examina un conjunto de políticas externas de Brasil desde el punto de vista de suas conexiones con las políticas tecnológicas en el segundo governo Vargas (1951-4) y en los goviernos Kubitschek (1956-61), Jânio Quadros e João Goulart (1961-4), Costa e Silva (1967-9), Médici (1969-74) y Geisel (1974-9). A partir de una discusión respecto los vínculos entre dependencia y autonomía tecnológica en las relaciones centro-periferia del capitalismo mundial, investiga las convergencias entre política externa y política tecnológica. Este trabajo plantea la hipótesis de que a lo largo del período de 1951-79 los formuladores de las políticas externa y tecnológica se hicieron cada vez más conscientes de la relación entre autonomía tecnológica y desarrollo, y buscaron crear sinergías entre una política y otra. El análisis de essos dos conjuntos de políticas permite comprender las prioridades y el verdadero alcance y obstáculos que una impuso a la otra.

Palabras-clave: dependencia tecnológica; autonomia; política externa.

\section{Introdução}

Um dos aspectos mais notáveis da contribuição latino-americana à discussão sobre o subdesenvolvimento é a importância atribuída pelos autores e autoras desse campo à dependência tecnológica como fator estruturante das relações centro-periferia. De fato, Prebisch (2011), Furtado (1974, 1992), Cardoso e Faletto (1970), Tavares (1972), Marini (2005) e Santos (1983), entre outros, não apenas indicaram em diversos momentos de suas obras as conexões entre subdesenvolvimento e dependência tecnológica, como também afirmaram a necessidade de reverter essa situação para superar o subdesenvolvimento dependente e subordinado.

Mais recentemente, o tema da dependência tecnológica como fator estruturante das relações centro-periferia tem recebido pouca atenção de estudiosos e de formuladores das políticas externa e tecnológica brasileiras. Tanto esses como aqueles abandonaram as noções de estrutura centro-periferia, dependência, subdesenvolvimento e autonomia e o exame de suas relações com o tema da tecnologia, e as substituíram por uma visão do sistema internacional composto pelos Estados nacionais, entidades isoladas cujas trajetórias de (sub)desenvolvimento dependem exclusivamente de si mesmos. Nessa visão, bastaria, para a superação da dependência tecnológica (e do subdesenvolvimento) a criação de um ambiente de negócios favorável à inovação (livre mercado, desregulação), ou a adesão plena aos sistemas de propriedade intelectual e aos acordos de comércio internacional vigentes (observância rigorosa de direitos de propriedade intelectual (PI), liberalização comercial para realização das vantagens comparativas) e a execução de políticas 
tecnológicas do lado da oferta (formação de recursos humanos, financiamento de infraestrutura laboratorial).

Nem sempre foi assim. O exame das políticas externa e tecnológica brasileiras entre as décadas de 1950 e 1970, período de auge e declínio do nacionaldesenvolvimentismo, revela que os formuladores daquelas políticas se comprometeram, de forma consciente e explícita, com a tarefa de alcançar a autonomia tecnológica para que a trajetória de desenvolvimento iniciada nos anos 1930 pudesse ter continuidade com maior autonomia econômica e política em relação aos países centrais. Contribuíram para isso a produção intelectual dos teóricos do subdesenvolvimento e da dependência, as experiências históricas de países bemsucedidos na redução da distância que os separavam dos países mais "avançados" e as tentativas contemporâneas de superação do subdesenvolvimento periférico por países do Terceiro Mundo.

Emprego o termo autonomia com um significado similar, mas ampliado, ao que a literatura sobre política externa brasileira usa (MOURA, 1980). Autonomia, em seu sentido mais geral, é a capacidade de um agente social - no caso, de um país — de definir seus objetivos e os meios de alcançá-los. A autonomia se desdobra em diferentes dimensões: política, econômica, cultural etc. Autonomia tecnológica é a capacidade de um país desenvolver conhecimento próprio e acompanhar os avanços de outros países na produção de conhecimento. Ela não equivale a autarquia tecnológica, que é a situação de independência total de um país de qualquer sistema tecnológico externo, mas ao estabelecimento de um amplo espaço de manobra histórica no qual, se assim o quiser, um país pode escapar em grau considerável ao monopólio tecnológico imposto por outros.

Devido à importância da tecnologia na divisão internacional do trabalho que estrutura o sistema capitalista mundial em centro e periferia, a busca pela autonomia tecnológica se torna condição essencial para a construção de um país desenvolvido e para a soberania econômica e política. Sem autonomia tecnológica, o desenvolvimento e a soberania são forçosamente parciais e efêmeros.

Consagrou-se na literatura de história das relações internacionais do Brasil a interpretação de que toda a política externa brasileira de 1930 até o presente foi orientada por um objetivo comum, o "desenvolvimento como vetor da política exterior" (CERVO, 2003, p. 12). Logo, seria de se supor que a política externa brasileira, em 
especial as autonomistas (PINHEIRO, 2013), isto é, aquelas voltadas para o fortalecimento da soberania nacional por meio do aumento da autonomia em todas suas dimensões, tenha atuado no sentido de apoiar o desenvolvimento tecnológico nacional, e que a política tecnológica, por sua vez, tenha buscado pontos de apoio na política externa brasileira.

Essa relação, contudo, nem sempre se deu de maneira direta. Houve momentos de maior e menor convergência entre as políticas externa e tecnológica, e essas variações explicam em grande parte os diferentes resultados alcançados pelo Brasil em seus esforços de desenvolvimento nacional e as idas e vindas do processo de desenvolvimento dos anos 1930 aos anos 1970.

Com essas questões em mente, analisarei as políticas exteriores e tecnológicas do segundo governo Vargas (1951-4) e dos governos Jânio Quadros e João Goulart (1961-4), Costa e Silva (1967-9), Médici (1969-74) e Geisel (1974-9) para identificar pontos de convergência e divergência entre as políticas externa e tecnológica brasileiras e discutir em que medida elas contribuíram para promover a construção da soberania política e econômica nacional por meio da autonomia tecnológica.

\section{Desenvolvimento e tecnologia na história da política externa brasileira: um consenso nada rigoroso}

Desenvolvimento e tecnologia são termos amplamente empregados na história da política externa brasileira e nos estudos sobre o nacionaldesenvolvimentismo. Hoje em dia, é lugar-comum apontar a centralidade que a busca pelo desenvolvimento teve ao longo da política externa brasileira durante o período nacional-desenvolvimentista, compreendendo, grosso modo, o meio século que vai da Revolução de 1930 até a crise da dívida externa em inícios da década de 1980, bem como a importância da política externa para o processo de desenvolvimento durante aquelas cinco décadas (MOURA, 1980; CERVO, 2003; VIZENTINI, 1995, 1998, 2012; PINHEIRO, 2013). A literatura sobre história da política externa brasileira identificou a busca pelo desenvolvimento como objetivo central dos esforços da diplomacia brasileira naquele período; a literatura sobre o período nacional- 
desenvolvimentista, por sua vez, apontou a relevância da política externa no processo de desenvolvimento nacional.

A condição periférica de um país dificulta a resolução interna das duas escassezes fundamentais do subdesenvolvimento: de capital e de tecnologia. $\mathrm{Na}$ década de 1930, o Brasil optou pelo financiamento externo dos capitais que seriam empregados no processo de desenvolvimento (FURTADO, 2003; SOUZA, 2008; PIRES, 2010). Nas cinco décadas seguintes, o Brasil aprofundou o recurso ao financiamento externo do processo de desenvolvimento, estratégia que encontraria seu fim na crise da dívida externa no começo dos anos 1980.

O enfrentamento do problema da escassez de tecnologia, no entanto, se desenrolou de modo diferente. De 1930 até 1945, o Brasil recorreu sobretudo à aquisição de tecnologia externa. A partir de então, e de modo crescente, ainda que não sem recuos pontuais, o Brasil passa a buscar o desenvolvimento interno de tecnologia com o objetivo de alcançar autonomia em produção tecnológica. $O$ desenvolvimento tecnológico interno se deu por meio da construção de um sistema de tecnologia, ciência e desenvolvimento industrial composto por instituições e políticas públicas de formação de recursos humanos e pesquisa. Por sua própria condição periférica, o Brasil jamais pode deixar de recorrer, em algum grau, à aquisição de tecnologia e conhecimento de outros países, fosse em razão de limitações tecnológicas ou restrições financeiras. A busca pela autonomia tecnológica passou de uma situação de quase total dependência externa para uma estratégia que combinou a aquisição de tecnologias estrangeiras e o desenvolvimento de capacidades tecnológicas internas. Coube à política externa viabilizar o acesso às tecnologias estrangeiras que o Brasil, por meio de sua política tecnológica, tentava dominar.

O desenvolvimento interno de tecnologia se dá com a formação de recursos humanos no país, a criação de universidades e centros de pesquisa e a construção de instituições de fomento à pesquisa e ao desenvolvimento industrial. $\mathrm{O}$ acesso e aquisição de tecnologias externas, por sua vez, ocorre com a atração de pesquisadores estrangeiros, o envio de brasileiros para estudarem em outros países, acordos de cooperação tecnológica e industrial e a atração de empresas estrangeiras para operarem no território nacional. 
As definições de desenvolvimento e tecnologia da literatura de política externa brasileira e de estudos sobre o nacional-desenvolvimentismo são insuficientes. Desenvolvimento é quase sempre entendido como crescimento econômico, sem que se discuta sua forma (se autônomo ou dependente), seus efeitos (concentrador ou distribuidor de renda) e sua dinâmica no médio e longo prazo (se sustentável ou se procedendo por arranques e recuos). Tecnologia, no mais das vezes, se não na totalidade, é entendida como equivalente a ganhos de produtividade, sem que se pergunte sobre as possibilidades de se alcançar um grau razoável de autonomia tecnológica, dada a posição periférica e dependente do país e o monopólio tecnológico dos países centrais. A rigor, os termos desenvolvimento e tecnologia são apresentados desprovidos de conteúdo que os defina. Assim, a relação entre desenvolvimento e tecnologia aparece, para grande parte da literatura que examinou a questão, como crescimento econômico por meio de ganhos de produtividade através da incorporação de tecnologia à economia do país.

O modo como desenvolvimento e tecnologia foram (mal) definidos por essa literatura deixa sem resposta uma série de perguntas fundamentais. De que modo a economia política mundial da tecnologia define o processo de desenvolvimento? Quais são as limitações internas e externas para a autonomia tecnológica e o desenvolvimento nacional? Por que a incorporação de tecnologia ao processo de desenvolvimento não é um processo neutro, mas determinado pelo monopólio tecnológico dos países centrais, portanto um campo de disputa política e econômica?

\section{A busca pela autonomia nas políticas externa e tecnológica}

A conexão entre dependência tecnológica e situação periférica indica a importância de examinar a relação entre o conjunto de políticas externas voltadas à inserção autônoma do Brasil nas relações internacionais e as políticas de desenvolvimento tecnológico coetâneas. A tese mais geral que anima este artigo é que uma política externa autonomista deve, idealmente, incorporar em algum grau elementos de uma política tecnológica autonomista, isto é, voltada à redução da dependência tecnológica do país, se aquela quiser atingir seus objetivos mais amplos de promoção do desenvolvimento e da soberania nacional. Uma política externa 
autonomista não pode prescindir de uma política tecnológica autonomista. Essas políticas são complementares e se reforçam mutuamente.

A inserção internacional de um país que não domina as tecnologias próximas à fronteira tecnológica será forçosamente dependente e subordinada às nações que dominam essas tecnologias. A dependência da política tecnológica autonomista de uma política externa autonomista ocorre porque, para um país distante da fronteira tecnológica, o processo de redução da distância da fronteira tecnológica (catch-up) deve lançar mão do desenvolvimento de capacidades tecnológicas próprias, mas não pode prescindir de acessar tecnologias estrangeiras, seja por mecanismos de mercado, seja por engenharia reversa, imitação, atração de empresas estrangeiras, formação de recursos humanos no exterior, colaboração em pesquisa e desenvolvimento ou outros mecanismos (cf. KIM, 2005; TOLEDO, 2017). Para os países periféricos, tecnologicamente dependentes dos países centrais, o dilema entre make e buy é falso. A autarquia tecnológica (make) é virtualmente impossível devido à interdependência dos processos de mudança tecnológica sob um capitalismo cuja escala é mundial. O acesso a tecnologias sob monopólio dos países do centro exclusivamente por mecanismos de mercado (buy), por sua vez, é a própria definição de dependência tecnológica, pois mantém o país na condição de usuário de uma caixa-preta tecnológica (ROSENBERG, 2006). O processo de construção da autonomia tecnológica é essencialmente um processo de aprendizagem e aquisição de competências que precisa tirar proveito das vantagens do atraso, lançando mão do recurso a tecnologias já existentes e sob domínio de outros países para poupar esforços de desenvolvimento tecnológico (TOLEDO, 2017).

Em seus incompletos ensaios de desenvolvimento, o Brasil se defrontou constantemente com a questão da dependência tecnológica e procurou enfrentá-la por meio tanto do domínio de capacidades tecnológicas próprias como pela obtenção de tecnologias estrangeiras pelos vários mecanismos possíveis. E os momentos em que o país buscou colocar em prática uma política externa autônoma quase sempre foram acompanhados pela execução de uma política tecnológica autônoma. Não se trata de coincidência: dependência tecnológica e dependência política e econômica são faces da mesma moeda.

Nem toda política tecnológica, contudo, resulta em autonomia tecnológica. O Brasil tem oscilado entre dois vetores cujos efeitos recíprocos têm variado 
imensamente ao longo do tempo. Esses vetores são, por um lado, o desenvolvimento tecnológico com vistas a reforçar a inserção internacional do Brasil como nação periférica no sistema capitalista mundial e, por outro, o desenvolvimento tecnológico que abre possibilidades de desenvolvimento autônomo e de superação da condição periférica. Incluem-se entre as primeiras as políticas e instituições de tecnologia e ciência voltadas a aprofundar a extroversão da produção agrária e extração de recursos naturais do país - como se vê, por exemplo, na incorporação de tecnologia para ampliar a área produtiva da agropecuária brasileira, reforçando, consequentemente, a inserção dependente do Brasil no sistema capitalista mundial na condição de país exportador de commodities agrícolas. Entre as segundas, estão as políticas e instituições que aproximam o Brasil da fronteira tecnológica contemporânea, abrindo brechas no monopólio tecnológico dos países centrais como se viu no caso do setor aeronáutico e nuclear brasileiros e da produção de vacinas.

Deve-se apontar, todavia, que o desenvolvimento tecnológico, ainda quando resulte em um primeiro momento no reforço da inserção subordinada da nação na economia capitalista mundial, nem por isso deixa de possuir um potencial de desdobramentos futuros que podem contribuir para a autonomia tecnológica e o desenvolvimento nacional se assim direcionados. Tudo dependerá do modo como serão mobilizados os elementos gerados pelo desenvolvimento tecnológico: se potencializando os vetores que nos levam em direção à autonomia, ou os que nos levam à dependência tecnológica. Trata-se de uma escolha essencialmente política realizar a transição de uma economia primário-exportadora para uma economia intensiva em tecnologia, por mais que essa mudança esteja muito longe de ser trivial.

Uma ressalva: todos os projetos nacionais de desenvolvimento que discuto neste artigo por meio da investigação das relações entre política externa e política tecnológica foram, salvo aquele enunciado nas Reformas de Base de João Goulart e que não foi adiante, cunhadas na forma de modernização conservadora. Nenhum daqueles projetos colocou-se o objetivo de rompimento com o capitalismo e o sistema mundial. A avaliação de seus resultados deve sempre levar em consideração esse aspecto, crucial para a compreensão dos limites do desenvolvimento brasileiro. 


\section{Convergências das políticas externa e tecnológica no Brasil, 1951-79²}

A literatura sobre história da política externa brasileira (daqui em diante, PEB) concorda ao apontar a forte conexão entre esta e a agenda de desenvolvimento nacional no século XX. Pinheiro, discutindo os paradigmas da PEB ao longo do século $X X$, afirma que esse período "[...] foi marcado por uma constante que se pode resumir brevemente como a busca pelo desenvolvimento" (Pinheiro, 2013, p. 8). Segundo Vizentini, "[...] coube a Vargas e aos governos populistas dos anos 1950 [...] a vinculação estratégica da política exterior às necessidades do processo de desenvolvimento econômico" (VIZENTINI, 2012, p. 11), ligação que seria aprofundado nas décadas de 1960 e 1970. Vizentini caracteriza a PEB entre 1951-64 como "um período de luta entre dois projetos, caracterizando uma fase de avanços e recuos entre os nacionalistas e os 'entreguistas'”, com os anos de 1951-54 (segundo governo Vargas) e 1961-4 (período da Política Externa Independente, PEI, de Jânio Quadros e João Goulart) como momentos de afirmação plena da conexão entre política externa, autonomia e desenvolvimento nacional, e os anos 1954-8 marcados "pela abertura econômica absoluta ao capitalismo internacional e pelo retorno do alinhamento automático em relação à diplomacia americana" (VIZENTINI, 2012, p. 20). Para Cervo,

A política exterior destinava-se a preencher requisitos desse desenvolvimento assim concebido [desenvolvimento como industrialização e crescimento econômico], trazendo de fora três insumos em apoio aos esforços internos: capital complementar à poupança nacional, ciência e tecnologia e mercados externos, com que transitar da substituição de importações à substituição de exportações (CERVO, 2003, p. 14).

Ainda que na PEB do século XX, e em especial durante o período desenvolvimentista, a preocupação com o desenvolvimento nacional tenha sido quase sempre constante, a atenção ao papel da tecnologia para o desenvolvimento e sua relação com a política externa nem sempre estiveram presentes ou resultaram em políticas tecnológicas condizentes com aquele objetivo. Será possível que a

\footnotetext{
${ }^{2}$ As informações sobre datas de criação de instituições de tecnologia, ciência e desenvolvimento industrial e implementação de políticas tecnológicas foram retiradas de diversas fontes, incluindo publicações oficiais das instituições citadas, tanto impressas como on-line. Recorri em especial, e extensamente, a Motoyama (2004), ao Centro de Memória do CNPq (http://centrodememoria.cnpq.br/cmemoria-index.html), à Cronologia do Desenvolvimento Científico, tecnológico e Industrial Brasileiro (MDIC, CNI/IEL e Sebrae Nacional, 2005) e ao CPDOC - Centro de Pesquisa e Documentação de História Contemporânea do Brasil (https://cpdoc.fgv.br/), da FGV.
} 
inconstância do alinhamento entre esses dois campos de políticas, tão fundamentais para a autonomia e o desenvolvimento nacional, explique em parte o caráter incompleto que marca a experiência histórica do Brasil em sua fase desenvolvimentista e a persistência do subdesenvolvimento e de nossa condição periférica? Quais foram as iniciativas mais bem-sucedidas? O exame das cinco políticas externas autonomistas executadas entre 1951-64 e 1967-79 oferece um caminho para responder a essas questões.

\section{Segundo governo Vargas (1951-4) e o lançamento das bases do sistema nacional de tecnologia: absorção de tecnologias externas e produção interna}

A década e meia que vai do início do segundo governo Vargas até o golpe de 1964 foi um período crítico para o desenvolvimento brasileiro. Superadas as fases iniciais da industrialização - industrialização espontânea, criação das indústrias de base, consolidação da indústria de bens de consumo -, os desafios para seu prosseguimento aumentavam. As exigências de capital e tecnologia eram muito maiores do que nas fases iniciais do processo. Em particular, o quase inexistente setor de bens de capital continuava a representar o maior gargalo para um crescimento industrial sustentável, como mostrou Tavares (1972), pois a expansão do setor de bens de consumo encontrava seu limite na baixa capacidade da indústria nacional de fornecer os bens de capital que poderiam levar à expansão da produção industrial. Esses tinham então que ser importados, o que cedo ou tarde resultava em uma crise cambial e, portanto, na impossibilidade de importar os bens de capital necessários para a expansão industrial. Isso gerava um novo ciclo de industrialização por substituição de importações daqueles bens que não podiam ser importados. A cada ciclo as exigências de capital, tecnologia e escala aumentavam significativamente em relação ao ciclo anterior, recolocando o problema em termos mais complexos.

O segundo governo Vargas (1951-4) procurou enfrentar esse gargalo aprofundando o processo de industrialização com ampla participação estatal e financiamento externo, tentando repetir na política externa a diplomacia da barganha do primeiro governo Vargas, que tão bons resultados obteve. A conjuntura internacional, no entanto, era completamente diferente daquela que prevaleceu ao longo do primeiro governo Vargas: os Estados Unidos estavam dedicados à 
consolidação de sua hegemonia, à reconstrução da Europa ocidental e do Japão, e à Guerra Fria com a União Soviética, não tendo naquele momento tempo nem interesse para se dedicarem à América Latina, o que impactava diretamente a capacidade de barganha brasileira (MOURA, 1980, 2012; CERVO E BUENO, 2017).

A expansão do sistema de tecnologia, ciência e desenvolvimento industrial no Brasil começa no imediato pós-guerra ainda durante o governo Dutra (1946-51) e prossegue na década de 1950 durante o segundo governo Vargas (1951-4). Em 1950 instalam-se as primeiras indústrias automobilísticas no país, e a campanha "O petróleo é nosso" é lançada. No mesmo ano, o Instituto Tecnológico de Aeronáutica (ITA) e o Centro Técnico Aeroespacial (CTA) são oficialmente criados.

Em 1951, em um dos últimos atos administrativos de Dutra, é fundado o CNPq, tendo como seu primeiro presidente o Almirante Álvaro Alberto, líder também do nascente programa nuclear brasileiro. No mesmo ano, mas já sob a presidência de Getúlio Vargas, foram criadas a Capes e a Comissão de Desenvolvimento Industrial. No ano de 1952 foi criado o BNDE, e teve início a prospecção de minérios radioativos no Brasil. Em 1953, cinco anos após o lançamento da campanha "O petróleo é nosso", foi fundada a Petrobrás. No ano de 1954, foi criado o Instituto de Pesquisa e Desenvolvimento (IPD) do CTA.

Foi também durante o segundo governo Vargas que foi criada a Comissão Mista Brasil-Estados Unidos (CMBEU), ativa entre 1951 e 1954 e responsável pela elaboração de uma ampla gama de estudos para embasar o planejamento do desenvolvimento brasileiro. A frustração brasileira em relação ao esperado, e não entregue, apoio dos Estados Unidos para 0 desenvolvimento nacional - tanto em termos de capital como de tecnologia, suporte que a criação da CMBEU parecia anunciar como certa - levaria Vargas a realizar um movimento duplo, no plano externo e no plano interno, de revisão de sua estratégia política. A partir da metade de seu segundo governo a política externa se tornaria mais autonomista, com a política econômica se afastando do liberalismo dos dois primeiros anos de governo e dobrando a aposta no desenvolvimento liderado pelo Estado (CERVO e BUENO, 2017).

O segundo governo Vargas lançou as bases do que viria a ser o sistema nacional de tecnologia. Naqueles primeiros momentos, os esforços se concentraram no desenvolvimento de capacidades de absorção de tecnologia externa, de onde a 
grande ênfase na criação de instituições de formação de recursos humanos nas áreas de ciência e tecnologia. Como parte desse conjunto de esforços, às instituições de formação de pesquisadores foram acrescentadas instituições de fomento do desenvolvimento industrial e empresas estatais em setores estratégicos. Essa base tecnológica, científica, institucional e industrial, articulada às políticas externas autonomistas das duas décadas seguintes, forneceria o ponto de partida para o desenvolvimento de políticas tecnológicas e produtivas voltadas à busca da modificação das formas de inserção do Brasil na divisão internacional do trabalho no sistema capitalista mundial.

Esse processo, contudo, não se desenvolveu de forma linear, mas sim por meio de idas e vindas. Os governos Café Filho (1954-6), Kubitschek (1956-61) e Castelo Branco (1964-7) abandonariam os esforços de desenvolvimento tecnológico interno, recorrendo à tecnologia externa, quase sempre por meio da atração de empresas estrangeiras, ou seja, submetendo-se ao monopólio tecnológico dos países centrais.

\section{Governo Juscelino Kubitschek (1956-61) e a reorientação da estratégia tecnológica: aquisição de tecnologias externas}

O contexto internacional mudaria novamente durante o governo de Juscelino Kubitschek (1956-61), com a consolidação de governos nacional-desenvolvimentistas em vários países da América Latina e a ascensão de movimentos comunistas na região, colocando o subcontinente no rol de espaços de atuação direta da política imperialista estadunidense. Com efeito, a América Latina, que havia sido marginalizada no sistema internacional nos quinze anos que se seguiram ao final da Segunda Guerra Mundial, voltou a ser região estratégica a partir da Revolução Cubana em 1959.

Além disso, ganhava corpo naquele momento uma das instituições centrais do capitalismo contemporâneo, a moderna empresa multinacional - não só estadunidenses, como também europeias (inglesas, francesas, alemãs, italianas) e japonesas - , que começou a estender de modo muito agressivo sua atuação para a periferia do capitalismo. Para superar as limitações de capital, tecnologia e escala que emperravam o processo de industrialização, Kubitschek recorreu à atração de 
empresas multinacionais, que dispunham daqueles fatores em abundância, reservando à indústria nacional um papel subordinado que dispensava em larga medida a necessidade de desenvolvimento tecnológico próprio. Assim, o novo padrão de industrialização com ampla associação ao capital externo, uma das marcas do Plano de Metas de Kubitschek (1956), se por um lado resolveu no curto prazo os problemas de falta de capital e tecnologia, por outro aprofundou a dependência tecnológica do Brasil em relação aos países centrais.

Em comparação com o segundo governo Vargas, no governo Kubitschek a preocupação com a autonomia tecnológica passou, assim, para o segundo plano. Kubitschek apostaria na atração de investimentos e tecnologia externos, sem, contudo, adotar políticas de absorção e desenvolvimento tecnológico interno. Se Vargas implementou, em conjunto com políticas de acesso e aquisição de tecnologias externas, políticas voltadas à redução da dependência tecnológica, Kubitschek centrou sua política de desenvolvimento tecnológico na aquisição de tecnologias sob monopólio dos países centrais e sua introdução na economia nacional por meio da atração de multinacionais. Em outras palavras, Vargas combinou aquisição de tecnologias externas (buy) com desenvolvimento tecnológico interno (make); Kubitschek apostou na aquisição de tecnologias externas (buy). Nesse sentido, a política de desenvolvimento tecnológico de Kubitschek insere-se naquela categoria de iniciativas que reforçam a dependência tecnológica, ao contrário daquela do segundo governo Vargas, conducente, pelo menos em seus esforços e intenções, à autonomia tecnológica.

Isso não significou a completa ausência de iniciativas de desenvolvimento tecnológico nacional, nem a interrupção das iniciativas anteriores. Entre outras iniciativas, foram criados em 1956 o Instituto de Energia Atômica, que depois mudaria o nome para Instituto de Pesquisas Energéticas e Nucleares (IPEN), a Comissão Nacional de Energia Nuclear (CBNEN), além de inúmeras ações na área nucelar, como aquisição de equipamentos e pesquisas minerais, e a Comissão Nacional Aeroespacial (CNAE).

À medida que o Plano de Metas era implementado, a questão da escassez de capital e tecnologia se tornou cada vez mais evidente. Em 1958, para tentar superar essas restrições, o governo Kubitschek propôs aos Estados Unidos a Operação PanAmericana (OPA), procurando angariar o apoio dos Estados Unidos para o 488 
prosseguimento do Plano de Metas em particular e do processo de desenvolvimento nacional como um todo. Como se sabe, a proposta da OPA foi recebida com pouco entusiasmo nos Estados Unidos, resultando somente na criação do Banco Interamericano de Desenvolvimento (BID). Apenas com a renovação do interesse estratégico da América Latina na esteira da Revolução Cubana os Estados Unidos iriam se dispor a oferecer apoio - ainda que modesto - ao processo de desenvolvimento dos países latino-americanos, com a Aliança para o Progresso.

\section{A Política Externa Independente dos governos Jânio Quadros e João Goulart (1961-4)}

Esses mesmos desafios - a necessidade de dar prosseguimento ao processo de industrialização em patamares que demandavam mais capital e tecnologia, ambos bastante escassos no país - e alternativas - dependência ou autonomia tecnológica, desenvolvimento subordinado ou soberano - se tornaram ainda mais prementes na década de 1960, mas nem por isso de enfrentamento mais fácil, malgrado todos os avanços da década e meia anterior.

Segundo Pinheiro, a "ênfase na questão do desenvolvimento" seria uma das principais características da Política Externa Independente (daqui em diante PEI) (2013, p. 35). Para Vizentini, a PEI "pode ser entendida como um instrumento do interesse diplomático nacional, isto é, como elemento de apoio do processo de desenvolvimento industrial brasileiro" (VIZENTINI, 2012, p, 28) e parte fundamental dos esforços para constituir a PEB como "um instrumento indispensável para a realização de projetos nacionais, no caso a industrialização e o desenvolvimento do capitalismo" (VIZENTINI, 2012, p. 29).

Os governos Jânio Quadros e João Goulart (1961-4) se depararam com grandes dificuldades que se refere ao problema do desenvolvimento nacional e da dependência tecnológica. Se por um lado a PEI trouxe para o centro de suas preocupações a relação entre política externa e desenvolvimento, explicitada inúmeras vezes nos discursos e documentos da PEI (Documentos da PEI, 2007 e 2008), por outro, a situação política altamente conturbada e virulenta que resultaria no golpe civil-militar de 1964 dificultou e por fim interrompeu qualquer resultado mais amplo e duradouro de iniciativas que articulassem efetivamente política externa e 
política tecnológica. Com efeito, se a questão do desenvolvimento nacional assume posição central nas formulações da PEI, sua vinculação com o problema da dependência tecnológica não chegou a ser claramente formulada, muito menos implementada, e foi abortada pelo golpe.

As referências ao problema da dependência tecnológico na PEI são bastante genéricas, por exemplo, nas menções à importância do domínio das tecnologias nucleares, mas não passam muito disso. Digno de nota por revelar compreensão sofisticada dos desafios com que os países periféricos se deparavam, ainda que sem maiores consequências concretas para o enfrentamento da questão naquele momento, foi o discurso do chanceler San Tiago Dantas à Câmara dos Deputados em novembro de 1961 a respeito do restabelecimento de relações diplomáticas do Brasil com a União Soviética. Naquela ocasião, Dantas apresentou as conclusões a que chegaram o Ministério das Relações Exteriores e a chancelaria argentina sobre a iminência de uma transição do que hoje chamamos paradigma tecnológico vigente que anularia as chances dos países em desenvolvimento de realizarem um catch-up tecnológico e produtivo com os países avançados, aprofundando o hiato tecnológico daqueles em relação a esses: Nós, os povos que hoje estamos conseguindo, à custa das mais duras penas,
chegar ao nível médio das nações industrializadas, estamos sob a ameaça
de que as nações plenamente desenvolvidas deem um novo e prodigioso
salto para diante, em que dificilmente poderemos acompanhá-las, tão
dispendiosos e tão complexos são os passos necessários para habilitar uma
nação a incorporar os progressos tecnológicos da era dominada pela física
nuclear e pela conquista do espaço cósmico (DOCUMENTOS DA PEI, 2007,
p. 202-203).

É bem verdade que a PEI, ponto culminante até aquele momento da política externa brasileira autonomista, sofreu as vicissitudes da crise política que desembocaria no golpe de 1964. Isso explica em parte seus limites: a consciência aguda dos desafios do desenvolvimento econômico manifestada em suas declarações não se transformou em ações concretas. O descompasso entre intenção e gesto predominou: discursos e planos de desenvolvimento econômico cresceram em tom e ambição, mas com pouca capacidade de realizações concretas no plano das políticas externa e interna.

A política de desenvolvimento tecnológico daqueles anos, portanto, foi bastante limitada, embora as pretensões fossem grandes. Dentre as ações mais 
importantes, o período foi marcado pela promulgação da lei de criação da Comissão Nacional de Energia Nuclear (CNEN) em 1962; pela criação do centro de pesquisas da Petrobrás no Rio de Janeiro, o CENPES (Centro de Pesquisas e Desenvolvimento Leopoldo Américo Miguez de Mello) em 1963; pela assinatura do Acordo Básico de Cooperação Técnica Brasil-Alemanha; pelo início da construção de instalações espaciais em Natal; e pelo começo da produção de radioisótopos e radiofármacos no Instituto de Pesquisas Energéticas e Nucleares (IPEN).

A promulgação da lei de criação da CNEN evidencia algum alinhamento entre a preocupação com a tecnologia nuclear manifestada na PEI e a política de desenvolvimento tecnológico, no caso, o programa nuclear brasileiro. Essa questão foi retomada com força e assumiu grande importância na política externa dos governos Costa e Silva, Médici e Geisel, em que o problema do desenvolvimento da tecnologia nuclear foi um dos pontos centrais, embora não tenha sido aprofundada à época da PEI.

Em termos de política tecnológica, os anos de 1961-4 não foram um período de grandes realizações: as mais relevantes foram em sua maioria resultado do amadurecimento das iniciativas que nasceram do intenso processo de construção institucional e desenvolvimento econômico e tecnológico da primeira metade da década de 1950 durante o segundo governo Vargas. A assinatura do Acordo Básico de Cooperação Técnica Brasil-Alemanha em 1963, embrião dos acordos futuros de cooperação científica e tecnológica dos governos militares com a Alemanha, em especial o Acordo Nuclear Brasil-República Federal da Alemanha, de 1975, pelos seus desdobramentos posteriores, talvez tenha sido a iniciativa mais importante do período na área tecnológica. $O$ balanço geral no tocante ao desenvolvimento tecnológico, no entanto, é bastante modesto.

Durante a vigência da PEI, as iniciativas de desenvolvimento tecnológico, fosse ele autônomo ou dependente - tanto por produção (make) como por aquisição (buy) - estavam largamente bloqueadas pelo contexto de acirramento das tensões políticas internacionais e pelo refluxo do processo de crescimento da economia nacional. É por isso que se observa na PEI uma profunda ambiguidade quanto ao papel da tecnologia no projeto de desenvolvimento nacional e especificamente na política externa. Por um lado, na dimensão discursiva, o desenvolvimento tecnológico aparece cada vez mais como problema que não se resume nem se resolve automaticamente 
por meio da industrialização (ARBIX, 2016), nem é sucedâneo do aumento da produtividade. Pelo contrário, fica cada vez mais claro que a continuidade da industrialização passa a depender do desenvolvimento tecnológico - consciência aguda e corretíssima das dificuldades a que o processo de industrialização por substituição de importações chegava naquele momento. Por outro lado, em um contexto internacional e nacional altamente adverso, foram poucas as iniciativas concretas de política tecnológica de maiores consequências durante a vigência da PEI. A PEI representou um aguçamento da consciência das implicações da dependência tecnológica sobre o projeto de desenvolvimento e autonomia nacional, mas não foi capaz de transformar essa consciência em ações políticas concretas.

Assim, o problema da dependência tecnológica, que começou a se fazer timidamente presente na dimensão discursiva da PEB durante a PEI, não chegou a ser frontalmente formulado nem enfrentado. Em relação às convergências entre política externa e desenvolvimento econômico e tecnológico durante a PEI, contudo, também se aplica a avaliação mais geral de Vizentini sobre aquela política:

Seu fracasso tem que ser relativizado [...] A Política Externa Independente revelou-se muito mais precoce que equivocada, pois muitos de seus postulados foram retomados pela própria diplomacia dos militares ao final da primeira metade dos anos 1970 com o chamado "pragmatismo responsável". (VIZENTINI, 2012, p. 31)

Os anos de 1961-4, portanto, foram um período de poucos avanços efetivos em direção à autonomia tecnológica que vinha sendo perseguida desde o princípio da década de 1950 pelo segundo governo Vargas.

\section{A Diplomacia da Prosperidade de Costa e Silva (1967-1969)}

Após a suspensão do projeto de desenvolvimento e autonomia tecnológica nacional representado pela guinada liberal do governo Castelo Branco, as políticas externa e tecnológica dos governos Costa e Silva, Médici e Geisel retomaram o projeto que se manifestara na PEI, avançando do discurso à ação.

A Diplomacia da Prosperidade de Costa e Silva (1967-1969) representou, segundo Vizentini, "uma ruptura profunda com o governo anterior [Castelo Branco] [...] como política externa voltada para a autonomia e o desenvolvimento, 
assemelhava-se muito à PEl" (2012, p. 45). A importância atribuída ao desenvolvimento tecnológico exprimiu-se em um importante conjunto de ações diplomáticas voltadas a dar concretude à política externa autonomista.

Para Gonçalves e Miyamoto,

A prioridade havia passado para o desenvolvimento. [...] Desacreditado o projeto de desenvolvimento como resultado da ajuda externa, este passou a ser pensado como fruto de um processo endógeno. [...] Dentre os obstáculos identificados pela diplomacia brasileira à escalada do desenvolvimento nacional, constavam como mais importantes: 1) as pretensões monopolizadoras das grandes potências sobre as tecnologias de ponta, especialmente sobre a da energia nuclear (GONÇALVES E MIYAMOTO, 1993, p. 221-222).

A Diplomacia da Prosperidade deu prosseguimento ao que seria o projeto de desenvolvimento tecnológico mais ambicioso e sensível nos governos seguintes: o avanço do programa nuclear brasileiro e sua aplicação para a produção de energia nuclear. De fato, junto com as tecnologias aeronáuticas, a área nuclear vai receber constante e dedicada atenção desde o imediato pós-guerra. ${ }^{3}$ Foram celebrados cinco acordos de cooperação na área nuclear: com Israel e Argentina em 1967, com Espanha e Índia em 1969, e, o mais relevante de todos, a assinatura com a República Federal da Alemanha do Acordo de Cooperação em Ciência e Tecnologia em 1969, que abriria caminho para a cooperação na área nuclear com aquele país. A recusa do Brasil em assinar o Tratado de Não-Proliferação Nuclear (TNP) em 1968 — por ser "injusto e discriminatório" - dá a exata medida da ambição do projeto de autonomia tecnológica que começava a se desenhar naqueles anos, e que seria aprofundado na década seguinte pelos governos Médici e Geisel.

No plano doméstico, a política tecnológica é também ambiciosa e efetiva. Em 1967 o CNPq elaborou seu primeiro Programa de Desenvolvimento Científico e Tecnológico (PDCT), implementado no quinquênio 1968-72. O PDCT era parte do Programa Estratégico de Desenvolvimento 1968-70 (PED) e representou a primeira política sistemática para a área de CTI no Brasil. O programa tinha como prioridades a formação de recursos humanos em nível de graduação e pós-graduação e a

\footnotetext{
${ }^{3}$ Nesse sentido, a venda/ entrega do negócio de aviação comercial da Embraer para a Boeing/ Estados Unidos, concretizada em 2019, mostra uma profunda descontinuidade nas prioridades conferidas ao desenvolvimento tecnológico aeronáutico nacional; a construção de Angra III e o Programa de Submarinos da Marinha do Brasil, ao contrário, indicam a continuidade dos esforços para o domínio da tecnologia nuclear.
} 
ampliação da infraestrutura de pesquisa do país. O PDCT também elegeu as áreas prioritárias para investimentos em CTI no Brasil: "agricultura, astronomia, biologia, ciências sociais, física, geologia, matemática, química e tecnologia, além de um item específico para o estudo da região amazônica" (Centro de Memória CNPq). O ano de 1967 viu ainda a criação da Financiadora de Estudos e Projetos (FINEP), a aprovação das Diretrizes da Política Nacional de Energia Nuclear, o contrato inicial estabelecido pela Comissão Nacional de Energia Nuclear (CNEN) para a construção de uma usina nuclear em Angra dos Reis e iniciativas no setor aeroespacial, com o desenvolvimento e prototipagem do foguete Sonda II.

Em 1968, por meio do CNPq, o governo colocaria em prática uma política de retenção de pesquisadores no país para tentar reverter a fuga de cérebros que se seguiu à repressão crescente promovida pela ditadura, que mudaria de patamar de brutalidade em dezembro daquele mesmo ano com a promulgação do Al-5. No setor aeroespacial, tiveram início projetos de desenvolvimento de propelentes sólidos para foguetes e de projetos de satélites, e realizou-se o voo inaugural do Embraer EMB 110 "Bandeirante", primeiro projeto comercial da Embraer, que seria fundada no ano seguinte, em 1969.

Aliás, entre as principais iniciativas do ano de 1969, seguramente a mais importante, ambiciosa e plena de consequências, ainda que hoje tenha passado por uma brutal reversão em razão da venda de sua área de aviação comercial, foi a criação da Embraer. Outra iniciativa importante e ainda hoje em funcionamento foi a criação do Fundo Nacional de Desenvolvimento Científico e Tecnológico (FNDCT, Decreto-lei 719, 31 de julho de 1969). Além disso, deve-se chamar a atenção para a grande quantidade de universidades estaduais e federais criadas no período, iniciativas que continuaram no governo Médici.

No que se refere às relações entre as políticas externa e tecnológica, viu-se no governo Costa e Silva uma grande convergência entre uma e outra. Além disso, o período também foi importante por causa de iniciativas como o estabelecimento das bases legais e orçamentárias e dos acordos de cooperação internacional que sustentaram as iniciativas de política externa e política tecnológica dos governos Médici e Geisel na década seguinte. 


\section{A Diplomacia do Interesse Nacional de Médici (1969-74)}

Não se deve pensar que a Diplomacia da Prosperidade de Costa e Silva (1967-9), a Diplomacia do Interesse Nacional de Médici (1969-74) e o Pragmatismo Responsável e Ecumênico de Geisel (1974-9) tenham sido iguais no alcance de suas ações pela busca pela autonomia. As três políticas em larga medida se complementarem de forma sequencial, com a primeira lançando as bases do que viria a ser de fato implementado pela segunda e pela terceira, em especial no que diz respeito ao estabelecimento de acordos bilaterais para transferência e desenvolvimento tecnológico. Vale lembrar que a iniciativa mais importante e plena de consequências em termos das conexões entre política externa e política tecnológica nos governos militares teve início com a assinatura do primeiro acordo de cooperação nuclear entre Brasil e Alemanha Ocidental nos meses finais do governo Costa e Silva (Cruz, 2015). O enfrentamento da dependência tecnológica assumiu importância crescente entre 1967 e 1979, com alguns dos lances mais ousados executados no governo Médici.

Com efeito, em sua Diplomacia do Interesse Nacional (1969-74), o governo Médici acentuou os traços desenvolvimentistas e autonomistas presentes na Diplomacia da Prosperidade de Costa e Silva, ainda que tenha abandonado os elementos terceiro-mundistas presentes nessa última (VIZENTINI, 2012). A Diplomacia do Interesse Nacional, apesar do alinhamento formal aos Estados Unidos, deu seguimento a uma série de aspectos autonomistas e desenvolvimentistas que vinham se configurando desde a PEI e foram retomados pela política externa do governo de Costa e Silva. Vizentini chama a atenção, entre outros aspectos, para a manutenção da recusa em assinar o TNP (posição que começava a se tornar um dos pontos doutrinários da política externa brasileira, só sendo revertida na década de 1990) e a grande ênfase na relação entre desenvolvimento e autonomia tecnológica, que passava pela atração de investimentos e tecnologias externas e pela construção de uma indústria bélica no país (VIZENTINI, 2012). Para tanto, a Diplomacia do Interesse Nacional lançou mão de uma política externa altamente pragmática ao se aproximar de potências capitalistas médias, iniciar a distensão com países da América 
Latina e a aproximação com países árabes, além de retomar as relações com países do campo socialista (VIZENTINI, 2012).

Entre as mais importantes iniciativas da política externa do governo Médici relacionadas à busca pela autonomia tecnológica estão aquelas voltadas à questão energética: o estabelecimento de acordo de cooperação técnica e científica com o Japão, inclusive na área nuclear (VIZENTINI, 2012), e a criação da Braspetro, braço internacional da Petrobrás voltado à exploração de petróleo e gás no exterior. Além dessas iniciativas, em 1972 o Brasil assinou acordo com os Estados Unidos para construção de uma usina nuclear em Angra dos Reis pela empresa Westinghouse, contrato rompido e substituído em 1975, no governo Geisel, pelo Acordo de Cooperação Nuclear Brasil-Alemanha, que previa a transferência de tecnologia para a construção de duas usinas nucleares em Angra. O rompimento do acordo com os Estados Unidos em favor do acordo com a República Federal da Alemanha causou crescentes fricções entre Brasil e Estados Unidos na segunda metade da década de 1970 (VIZENTINI, 2012).

A diplomacia nuclear e tecnológica da década de 1970 é bastante ilustrativa das ambições por desenvolvimento, autonomia tecnológica e soberania nas políticas externas daquele período. A licitação internacional para construção de usinas nucleares no ano de 1971 foi vencida pela empresa estadunidense Westinghouse, indicando a possibilidade muito concreta de aprofundamento da cooperação nuclear do Brasil com os Estados Unidos e a exclusão dos demais países com quem o Brasil vinha estabelecendo acordos de cooperação na área. Contudo, as dificuldades referentes à limitada transferência de tecnologia nuclear para o Brasil nos acordos com os Estados Unidos, bem como a nova estratégia internacional brasileira, calcada em uma política externa cujo objetivo declarado era diversificar o leque de relações internacionais do país em um contexto de crise energética e econômica global, mantiveram a Alemanha no jogo. Em 1975, Brasil e República Federal da Alemanha assinaram o Acordo de Cooperação Nuclear, que seria seguido em 1976 pelo Acordo Comercial para a realização de empréstimos e contratos para a construção das usinas de Angra I e Angra II, implicando a anulação da licitação que havia sido vencida pela Westinghouse em 1972. As pressões estadunidenses para inviabilizar o acordo nuclear Brasil-Alemanha foram enormes, com investidas diplomáticas contra os dois países. A transferência de tecnologias sensíveis de enriquecimento de urânio da 496 
Alemanha para o Brasil foi supostamente impedida pelos Estados Unidos, obrigando - Brasil a acelerar seus vários projetos de desenvolvimento de tecnologias de enriquecimento de urânio, que vinham ocorrendo em paralelo nas três Forças Armadas. No começo da década de 1980 o projeto da Marinha do Brasil se consolidou como trajetória tecnológica mais promissora, levando finalmente ao domínio da tecnologia em meados da década de 1980 e à liderança definitiva do programa nuclear brasileiro pela Marinha (VIZENTINI, 2012).

No que se refere à política de desenvolvimento tecnológico e científico no âmbito doméstico, entre as principais iniciativas do governo Médici estão a criação do Instituto Nacional de Propriedade Industrial (INPI), em 1970, e em 1971 a criação do Instituto Nacional de Pesquisas Espaciais (INPE) e a aprovação pelo Congresso da Lei 5.470, que autorizou a Comissão Nacional de Energia Nuclear a criar a Companhia Brasileira de Tecnologia Nuclear (CBTN), responsável pela construção e operação das usinas nucleares brasileiras. O ano de 1972 foi marcado pelo lançamento do I Plano Nacional de Desenvolvimento (I PND), que deu grande ênfase à implantação de infraestrutura e investimentos em desenvolvimento tecnológico, industrial e científico para sustentar o crescimento da economia brasileira nos anos seguintes. Ainda em 1972 foi criado o Sistema Nacional de Ciência e Tecnologia e a assinatura de um acordo para troca de urânio in natura do Brasil por urânio enriquecido dos Estados Unidos, sem previsão, no entanto, de qualquer espécie de transferência de tecnologia. Em 1973, foi lançado o I Plano Nacional de Desenvolvimento Científico e Tecnológico ( І РBCT), e teve início o desenvolvimento de álcool combustível na Unicamp, bem como o prosseguimento de pesquisas para o desenvolvimento de tecnologia de enriquecimento de urânio.

Provavelmente o evento mais importante do ano de 1973, contudo, no que diz respeito ao desenvolvimento tecnológico e econômico nacional, bem como ao padrão de inserção da economia brasileira na economia mundial pelas próximas décadas, foi a criação da Embrapa, instituição central do agronegócio brasileiro por seu papel no desenvolvimento e transferência de tecnologia para o setor - caso que também se enquadra naquela categoria de iniciativas de desenvolvimento tecnológico que reforçam o padrão histórico de inserção subordinada do Brasil na economia global, ainda que esse não fosse seu objetivo. 


\section{O Pragmatismo Responsável e Ecumênico de Geisel (1974-9)}

O governo Geisel (1974-9) representou um ápice dos esforços de desenvolvimento econômico e tecnológico autônomos e soberania política e econômica, ao qual se seguiu interrupção abrupta e declínio acelerado a partir da crise da dívida externa em inícios dos 1980. No plano doméstico, o milagre econômico começava a perder força; no plano internacional, o primeiro choque do petróleo, em 1973, mergulhou a economia global em uma crise da qual os países centrais só começariam a sair nos primeiros anos da década seguinte, mesma época da piora da crise nos países periféricos na sequência do choque de juros do Federal Reserve Bank dos Estados Unidos, que gerou a explosão das dívidas externas da América Latina, e do encerramento do ciclo nacional-desenvolvimentista. Segundo Vizentini, apesar das adversidades nos contextos nacional e internacional, o governo Geisel,

longe de adotar uma estratégia defensiva, preparou um aprofundamento do processo de industrialização por substituição de importações, com vistas a tornar o país autossuficiente em insumos básicos e, se possível, em energia (VIZENTINI, 2012, p. 50).

O II PND, lançado em 1974, deu corpo a essa estratégia. A busca pela autonomia econômica e tecnológica ganhou impulso em uma série de iniciativas, como a construção de hidrelétricas, o desenvolvimento de novos polos petroquímicos, o Proálcool e o início da construção de usina nuclear de Angra I, além de dobrar as apostas no desenvolvimento de tecnologias de enriquecimento de urânio, naquele momento ainda não dominadas pelo Brasil. A política externa do Pragmatismo Responsável e Ecumênico de Geisel daria prosseguimento à estratégia de redução do alinhamento da PEB em relação aos Estados Unidos, ao dar continuidade à política externa de Médici de aproximação não só com outras potências capitalistas, mas também com países do campo socialista, com destaque para a China, e com países árabes produtores de petróleo. Além disso, houve a retomada de certas inclinações terceiro-mundistas, patentes no reconhecimento das independências e no estabelecimento de relações diplomáticas com nações africanas recémindependentes e na continuação da distensão com países da América Latina. $O$ governo Geisel também continuou o movimento duplo de afastamento em relação aos 
Estados Unidos e aproximação da Alemanha na área nuclear, que vinha sendo executado desde o governo Médici (LIMA, 2018).

No plano da política tecnológica, as principais iniciativas do governo Geisel foram, além do II PND, que vigorou entre 1975 e 1979 e que elencou entre seus objetivos o desenvolvimento interno de tecnologia, a consolidação do Sistema Nacional de Desenvolvimento Científico e Tecnológico, o II Plano Básico para o Desenvolvimento Científico e Tecnológico, a criação do Programa Nacional do Álcool (Proálcool) e a transformação da Empresa Digital Brasileira (DIGIBRÁs) na Cobra S.A., em 1974. Em 1975 foi estabelecido o já citado Acordo Nuclear Brasil-Alemanha, especificando as áreas e tecnologias que seriam objeto de cooperação e transferência entre os dois países, que incluíam mineração e beneficiamento de urânio, produção de reatores nucleares, enriquecimento de urânio e sua transformação em combustível nuclear. Como todo processo de transferência tecnológica, este também ficou muito aquém das promessas tratadas nos acordos. No ano de 1976, foi instituído o PRONUCLEAR, política de formação de recursos humanos na área nuclear.

Apesar dos esforços nas áreas de desenvolvimento industrial e tecnológico empreendidos pelo Brasil na segunda metade da década de 1970, cujo ápice foi o II PND, e dos importantes resultados alcançados, o final da década assistiu ao colapso do nacional-desenvolvimentismo e das ambições de autonomia tecnológica e soberania política e econômica. A atualização do parque produtivo e do sistema tecnológico nacional atingiu plenamente suas metas: completar o processo de industrialização e dominar o paradigma tecnoeconômico vigente, o das tecnologias metal-mecânicas baseadas na grande empresa industrial de produção em massa.

Infelizmente para o Brasil, justo quando o país completava seu catch-up e se aproximava da fronteira tecnológica dominada pelos países centrais, estes iniciavam a transição para um novo paradigma tecnoeconômico, o das tecnologias de informação e comunicação baseadas em microprocessadores (PEREZ, 2009). Como os paradigmas são incomensuráveis entre si, isto é, como o domínio das tecnologias de um paradigma tecnoeconômico não são transferíveis automaticamente para emprego no domínio das tecnologias de outro paradigma, o Brasil ficou para trás em relação aos países do centro, malgrado seus esforços pontuais para dominar as tecnologias do novo paradigma. Seria preciso que o país tivesse condições tecnológicas, industriais, científicas e institucionais para realizar uma atualização 
muito ampla e profunda da estrutura tecnoprodutiva brasileira. No entanto, àquela altura o país já estava sem fôlego depois da marcha forçada do II PND (CASTRO E SOUZA, 2008). As tentativas de dominar essas novas tecnologias, como a criação de uma nascente indústria de informática e políticas de proteção do mercado nacional por meio da Política Nacional de Informática (PNI, aprovada em 1984), não tiveram a menor chance de reduzir a distância cada vez maior que os países líderes dessa revolução tecnológica abriam em relação aos países da periferia.

\section{Conclusão: política externa, autonomia tecnológica e soberania política e econômica}

As políticas externas do segundo governo Vargas (1951-4) e dos governos Kubitschek (1956-61), Jânio Quadros e João Goulart (1961-4), Costa e Silva (19679), Médici (1969-74) e Geisel (1974-9) caracterizaram-se pela progressiva incorporação do problema da autonomia tecnológica ao discurso e à ação da política externa brasileira. Podemos dizer o mesmo sobre a política tecnológica, cujos formuladores estavam crescentemente preocupados com a autonomia tecnológica e a soberania política e econômica, e conscientes da necessidade de acessar e absorver tecnologia externa.

Há elementos, portanto, para confirmar a hipótese que moveu este artigo: os formuladores da política externa e da política tecnológica nesses períodos estavam cientes da relação entre desenvolvimento, autonomia tecnológica e soberania, e buscaram criar sinergias entre uma política e outra, na tentativa de desenvolver o país. Além disso, foi possível observar que a consciência dessa relação aumentou progressivamente, começando por iniciativas de construção das instituições e políticas públicas de absorção e desenvolvimento tecnológico na década de 1950 no segundo governo Vargas e terminando por configurar iniciativas de grande impacto em fins da década de 1960 e durante toda a década de 1970 nos governos Costa e Silva, Médici e Geisel. Houve também interregnos em que a estratégia de desenvolvimento tecnológico ou enfatizou a aquisição de tecnologias externas, caso do governo Kubitschek, ou foi barrada pela situação de paralisia decisória, como a que definiu os governos Jânio e João Goulart, ou foi considerada desimportante, como no governo Castelo Branco, fases em que pouco esforço se dedicou à superação da dependência tecnológica, problema fundamental do desenvolvimento periférico. 
Entre os anos 1951-4, 1961-4 e 1967-79 o Brasil executou políticas externas ousadas e não-convencionais em contextos internacionais altamente desfavoráveis, o que mostra a importância naqueles momentos da ação política e da ideologia como elemento de orientação da ação na PEB. Nesse sentido, fica claro que a relevância progressiva atribuída ao problema de autonomia tecnológica no segundo governo Vargas e nos governos Jânio Quadros e João Goulart, Costa e Silva, Médici e Geisel dependeu em grande medida das inclinações ideológicas dos grupos no poder, primeiro o nacional-desenvolvimentismo trabalhista, democrático e popular e depois o nacional-desenvolvimentismo castrense, conservador e elitista guiado por considerações de segurança nacional e sonhos de Brasil Potência.

Em meados da década de 1970, o Brasil foi pego no contrapé de seus esforços de desenvolvimento tecnológico e industrial pela transição do paradigma tecnológico da grande indústria metal-mecânica para o das tecnologias da informação e comunicação (PEREZ, 2009), e os esforços brasileiros de catch-up produtivo e tecnológico se tornaram em grande medida obsoletos e irrelevantes. Desde então, o subdesenvolvimento e a dependência econômica e tecnológica foram recolocados como condição "normal" de nossa inserção internacional.

Ao longo das décadas de 1980 e 1990, qualquer esforço no sentido de construção da autonomia tecnológica e soberania política e econômica estiveram interditados. Primeiro, por questões de força maior, em razão da crise da dívida externa e da situação de deterioração acelerada da economia nacional. Segundo, pela pressão dos Estados Unidos para o desmonte do arcabouço legal, institucional, tecnológico e empresarial do nascente setor de informática brasileiro. Finalmente, por opção, à medida em que as classes dominantes brasileiras aderiam ao neoliberalismo e iam aceitando a condição de periferia desindustrializada exportadora de bens primários do país.

Nos anos 2000, as políticas externa e tecnológica do governo Lula (200310) e Dilma (2011-6) retomaram certo ativismo na dimensão da autonomia tecnológica, se bem que em um contexto internacional inteiramente diferente e adverso. Os esforços para realizar a atualização da estrutura produtiva e tecnológica do país, no entanto, mostraram-se insuficientes face ao hiato do Brasil em relação aos países centrais. 
Atualmente, assistimos à anulação de qualquer pretensão autonomista guiada pelo interesse nacional na política externa e o ataque violento ao sistema nacional de ciência, tecnologia e inovação. Tudo parece indicar que já embarcamos em nossa viagem de volta ao passado, ao Brasil pré-1930, fazendão exportador de commodities e importador de bens industrializados, caminho que nos levará à condição de neocolônia (Barbosa, Toledo et al, 2017; Toledo 2019; Osório, 2014).

Nesses quase noventa anos que separam 0 nascimento do nacionaldesenvolvimentismo do presente, o problema da dependência tecnológica se tornou mais, e não menos, relevante para o desenvolvimento das nações. A dimensão tecnológica na reflexão e ação dos formuladores e executores da política externa brasileira, por consequência, se tornou mais relevante e precisará ser devidamente enfrentada se o país quiser superar seu estado de dependência econômica e tecnológica crônica e não sucumbir a uma situação de desindustrialização, reprimarização produtiva e estagnação dos ganhos de produtividade. Isso vale para a incorporação de preocupações com a política externa por parte dos formuladores e executores da política tecnológica, uma das dimensões essenciais do desenvolvimento tecnológico. Às vésperas do bicentenário da Independência, é preciso, mais do que nunca, ter clareza de que uma política externa autônoma não pode prescindir de uma política tecnológica autônoma.

\section{Referências}

ARBIX, Glauco. "2002-2014: Trajetória da inovação no Brasil Avanços, indefinições e instabilidade nas políticas públicas de fomento à inovação e tecnologia". Friedrich Erbert Stiftung Brasil, Análise n. 17/2016, 2016.

CARDOSO, Fernando Henrique, FALETTO, Enzo. Dependência e desenvolvimento na América Latina: Ensaio de interpretação sociológica. $7^{a}$ edição, Rio de Janeiro, Zahar Editores, 1970.

CASTRO, Antônio Barros de, SOUZA, Francisco Eduardo Pires de. A economia brasileira em marcha forçada. Rio de Janeiro, Editora Paz e Terra, 2008.

CERVO, Amado Luiz, BUENO, Clodoaldo História da política exterior do Brasil. $4^{\mathrm{a} e d i c ̧ a ̃ o ; ~ B r a s i ́ l i a: ~ E d i t o r a ~ U n B, ~} 2017$.

CERVO, Amado Luiz. "Política exterior e relações internacionais do Brasil: enfoque paradigmático". Revista Brasileira de Política Internacional. 46, 2: 5-25, 2003. 
CNPq, Centro de Memória CNPq: http://centrodememoria.cnpq.br/cmemoriaindex.html. Acessado em 15 de maio de 2019.

CPDOC, Centro de Pesquisa e Documentação de História Contemporânea do Brasil, FGV: https://cpdoc.fgv.br/). Acessado em 15 de maio de 2019.

CRUZ, Eduardo Lucas Vasconcelos. "Antecedentes do Acordo Nuclear BrasilAlemanha". Revista UNILUS Ensino e Pesquisa, v. 12, n. 27: 16-27, 2015.

FRANCO, Álvaro da Costa. DOCUMENTOS DA PEI, vol. I. 1ª edição, Brasília, Funag, 2007.

FRANCO, Álvaro da Costa. DOCUMENTOS DA PEI, vol. II. $1^{\text {a }}$ edição, Brasília, Funag, 2008.

FURTADO, Celso. Brasil: a construção interrompida. $1^{\text {a }}$ edição, Rio de Janeiro, Paz e Terra, 1992. Nacional, 2003

Celso. Formação Econômica do Brasil. São Paulo: Companhia Editora , Celso. O mito do desenvolvimento econômico. $5^{\text {a }}$ edição, Rio de Janeiro, Paz e Terra, 1974.

GARCIA, Eugênio Vargas. Cronologia das relações internacionais do Brasil. $2^{\mathrm{a}}$ edição, Rio de Janeiro, Contraponto Editora, 2005.

GONCALVES, Williams da Silva MYAMOTO, Shiguenoli. "Os militares e a política externa brasileira - 1964-1984". Estudos Históricos, Rio de Janeiro, vol 6, 1993.

HARVEY, David. "The 'New' Imperialism: Accumulation by Dispossession”. Socialist Register, vol. 40: 63-87, 2009.

KIM, Linsu. Da imitação à inovação - $A$ dinâmica do aprendizado tecnológico da Coreia. Campinas: Editora da Unicamp, 2005.

LIMA, Sérgio Eduardo Moreira. O Pragmatismo Responsável na visão da diplomacia e da academia. Brasília: Fundação Alexandre de Gusmão, 2018.

MANZUR, Tânia Maria Pechir Gomes. "A Política Externa Independente (PEI): Antecedentes, apogeu e declínio”. Lua Nova, 93: 169-199, 2014.

MARINI, Ruy Mauro. "Dialética da dependência", in R. Traspadini e J. P. Stedile (org.), Ruy Mauro Marini: Vida e Obra. São Paulo, Editora Expressão Popular, 2005.

MDIC, CNI/IEL E SEBRAE NACIONAL. Cronologia do Desenvolvimento Científico, tecnológico e Industrial Brasileiro - 1938-2003. Brasília, MDIC, CNI/IEL E SEBRAE NACIONAL, 2005. 
MDIC. Cronologia do desenvolvimento científico, tecnológico e industrial brasileiro, 1938-2003. $1^{\text {a }}$ edição Brasília, MDIC, 2003.

MOTOYAMA, Shozo (org.). Prelúdio para uma história - Ciência e tecnologia no Brasil. São Paulo, Edusp, 2004.

MOURA, Gerson. Autonomia na dependência: a Política Externa Brasileira de 19351942. Rio de Janeiro: Editora Nova Fronteira, 1980.

MOURA, Gerson. Relações Exteriores do Brasil 1939-1950: Mudanças na natureza das relações Brasil-Estados Unidos durante e após a Segunda Guerra Mundial. Brasília: Fundação Alexandre de Gusmão, 2012.

OSÓRIO, Jaime. O Estado no centro da mundialização: a sociedade civil e o tema do poder. São Paulo: Outras Expressões, 2014.

PEREZ, Carlota. "Technological revolutions and techno-economic paradigms". Working Papers in Technology Governance and Economic Dynamics no. 20: 1-15, 2009.

PINHEIRO, Letícia de Abreu. Política externa brasileira. $2^{a}$ edição, Rio de Janeiro, Zahar, 2013.

PIRES, Marcos Cordeiro. Economia Brasileira: da colônia ao governo Lula. São Paulo: Saraiva, 2010.

PREBISCH, Raúl. O Manifesto Latino-Americano e outros ensaios. Rio de Janeiro: Contraponto Editora, 2011.

ROSENBERG, Nathan. Por dentro da caixa-preta - Tecnologia e economia. Campinas: Editora da Unicamp, 2006.

SANTOS, Teotônio dos. Revolução Científico Técnica e Capitalismo Contemporâneo. São Paulo: Editora Vozes, 1983.

SOUZA, Nilson Araújo de. Economia Brasileira Contemporânea. $2^{a}$ Edição Ampliada. São Paulo: Editora Atlas, 2008.

TAVARES, Maria da Conceição. "A retomada da hegemonia norte-americana". Revista de Economia Política. V.5, n.2: 5-15, 1985.

Maria da Conceição. Da substituição de Importações ao Capitalismo Financeiro. $1^{a}$ edição, Rio de Janeiro Zahar Editores, 1972.

TOLEDO, Demétrio G. C. de. "Catch-up, tecnologia, instituições e empresas: desenvolvimento como aquisição de competências". Revista Brasileira de Informação Bibliográfica em Ciências Sociais - BIB, São Paulo n. 80, 2017. 
VIZENTINI, Paulo Fagundes. "O Brasil e o Mundo: a política externa e suas fases". Ensaios FEE. Porto Alegre, v. 20, p. 134-154, 1999.

, Paulo Fagundes. A política externa do regime militar brasileiro. Porto Alegre: Editora da UFRGS, 2011.

, Paulo Fagundes. Relações Exteriores do Brasil: o nacionalismo, da Era Vargas à Política Externa Independente (1930-1964). Petrópolis: Editora Vozes, 2004.

, Paulo Fagundes. Relações Internacionais do Brasil: de Vargas a Lula. 3 ed. São Paulo: Fundação Perseu Abramo, 2012.

Petrópolis: Éditora Vozes, 1995.

Recebido em: 06/07/2019

Aprovado em: 23/04/2020 